\title{
Biotinidase deficiency: clinical and genetic studies of 38 Brazilian patients
}

\author{
Taciane Borsatto ${ }^{1,2}$, Fernanda Sperb-Ludwig ${ }^{3,4}$, Louise LC Pinto ${ }^{5}$, Gisele R De Luca ${ }^{5}$, Francisca L Carvalho ${ }^{5}$, \\ Carolina FM De Souza ${ }^{6}$, Paula FV De Medeiros ${ }^{7}$, Charles M Lourenço ${ }^{8}$, Reinaldo LO Filho ${ }^{9}$, Eurico C Neto ${ }^{10}$, \\ Pricila Bernardi ${ }^{11}$, Sandra Leistner-Segal ${ }^{3,6}$ and Ida VD Schwartz ${ }^{1,2,6,12^{*}}$
}

\begin{abstract}
Background: Biotinidase deficiency (BD) is an inborn error of metabolism in which some genetic variants correlate with the level of enzyme activity. Biotinidase activity, however, may be artifactually low due to enzyme lability, premature birth, and jaundice; this hinders both phenotypic classification and the decision to implement therapy. This study sought to characterize the clinical and genetic profile of a sample of Brazilian patients exhibiting reduced biotinidase activity.

Methods: This observational, multicenter study used a convenience sampling strategy, with sequencing of exons 2, 3, and 4 of the BTD gene.

Results: The sample comprised 38 individuals with biochemical phenotypes defined a priori on the basis of biotinidase activity in serum/plasma ( 2 with profound deficiency, 9 with partial deficiency, 15 heterozygous, 1 borderline between partial deficiency and heterozygosity, 2 borderline between heterozygous and normal) or dried blood spot sample ( $n=9$, all with unspecified deficiency). Most patients were from Southern Brazil $(n=29 / 38)$ and were identified by neonatal screening $(n=33 / 38)$. Parental consanguinity was reported in two cases. The most commonly found genetic variants were c.1330G > C (p.D444H), c.755A > G (p.D252G), and c.[511G > A;1330G > C] (p. [A171T;D444H]), with allele frequencies of 50\%, 9.4\%, and 5.4\% respectively. Three novel pathogenic variants were identified (c.119 T > C or p.L40P, c.479G > A or p.C160Y, and c.664G > A or p.D222N). Twenty-nine patients had two pathogenic variants detected (with cis/trans status ascertained in 26/29), six had only one variant, and three had no pathogenic variants detected. Genotyping confirmed the original phenotypic classification based on enzyme activity in 16/26 cases. Three polymorphic variants were identified in control individuals, of which two were nonpathogenic (c.1171C > T or p.P391S and c.1413 $\mathrm{T}>\mathrm{C}$ or p.C471C, with a frequency of $1.5 \%$ and $5.5 \%$ respectively) and one pathogenic (c.1330G > C, frequency 4\%).

Conclusions: Our findings suggest that partial BD is the most common form of BD in Brazil, and expand current knowledge on the allelic heterogeneity of this condition.
\end{abstract}

Keywords: Low biotinidase, Genetic variants, Neonatal screening, Brazil

\section{Background}

Biotinidase deficiency (BD, EC 3.5.1.12) is an autosomal recessive disease in which both the absorption of biotin from dietary sources and its reuse/recycling are impaired. This leads to a deficiency in biotin-dependent enzymes, such as propionyl-CoA carboxylase (EC 6.4.1.3), $\beta$-methylcrotonyl-CoA carboxylase (EC 6.4.1.4), pyruvate carboxylase

\footnotetext{
* Correspondence: idadschwartz@gmail.com

${ }^{6}$ Medical Genetics Service, Hospital de Clínicas de Porto Alegre (HCPA), Rua

Ramiro Barcelos, 2350, 90035-903 Porto Alegre, Brazil

Full list of author information is available at the end of the article
}

(EC 6.4.1.1), and acetyl-CoA carboxylase (EC 6.4.1.2) [1,2]. Treatment, which consists of oral administration of free biotin, is simple and effective when started early (e.g., before the onset of symptoms). If treatment is delayed, there is a risk of irreversible damage (including hearing and vision loss and mental retardation) and even death [3-5]. The diagnosis of $\mathrm{BD}$ is confirmed by measurement of biotinidase activity in plasma or serum. This test enables classification of patients as having profound (or total) BD (residual activity $<10 \%$ ) or partial BD (activity within $10-30 \%$ of average normal activity in serum). Heterozygous individuals have enzyme activity levels

C Biomed Central

(c) 2014 Borsatto et al.; licensee BioMed Central Ltd. This is an Open Access article distributed under the terms of the Creative Commons Attribution License (http://creativecommons.org/licenses/by/4.0), which permits unrestricted use, distribution, and reproduction in any medium, provided the original work is properly credited. The Creative Commons Public Domain Dedication waiver (http://creativecommons.org/publicdomain/zero/1.0/) applies to the data made available in this article, unless otherwise stated. 
between those of affected patients and those of homozygous normal individuals [2]. This classification plays an important role in instituting therapy, as patients with profound BD should be treated and heterozygous individuals should not; there is no consensus on the need for treatment of patients with partial BD [6].

However, enzyme testing is subject to interfering factors that can produce artifactually low results, such as the lability of biotinidase [7] and the direct correlation between enzyme activity and gestational age and even with postnatal age [8]. Furthermore, jaundiced neonates may have reduced biotinidase activity [9]. Analysis of the $B T D$ gene is important, particularly to elucidate the diagnosis when repeated enzyme testing yields discordant results [10], in the assessment of premature infants with reduced biotinidase activity, and in the assessment of infants who have received blood transfusions [6]. Table 1 provides a review of what is known from the literature about the association between the biochemical phenotype and genotype in BD.

This study seeks to describe the clinical and genetic profile of a sample of Brazilian patients presenting reduced biotinidase activity.

\section{Methods}

This is a multicenter, observational, cross-sectional study with a convenience sampling strategy. The study protocol was approved by the ethics committee of Hospital de Clínicas de Porto Alegre (HCPA), and all patients and/or their legal guardians provided written informed consent.

The study sample comprised 38 unrelated subjects (21 male), aged 1 month to 18 years, who were recruited from several regions of Brazil (29 from the South, 3 from the Southeast, and 6 from the Northeast) during 20122013 by contacting Brazilian medical geneticists throughout the mailing list of the Brazilian Medical Genetics Society. The criterion for inclusion was reduced biotinidase activity (below the lower reference limit of the testing laboratory). Clinical variables such as age, biotinidase activity, and symptoms were obtained by a review of medical records and by a data collection form filled out by the referring physicians. For genetic analysis, blood was collected from patients and their parents into EDTA-containing tubes. Overall, samples from both parents were available for 27 patients, samples from only one parent were available for 6 patients, and 5 patients had no parental samples available. Anonymous samples from 100 healthy, adult controls from Southern Brazil were tested for the c.1330G > C (p.D444H) variant and for all novel variants first described in the present study.

\section{Biotinidase activity}

Patients had undergone enzyme activity testing at four different laboratories (A, B, C, and D), one of which (laboratory $A, n=9 / 38$ patients) only carries out filter-paper testing, a technique that cannot quantitate the degree of BD and expresses activity in units (U) (Neonatal Biotinidase kit, PerkinElmer ${ }^{\circ}$, Wallac Oy, Turku, Finland). In these cases, patients were diagnosed by the attending staff as having BD after three consecutive abnormal tests (below the 70U cutoff), and were thus not classified into partial or profound BD. The activity presented in this study is the average of the three tests (Table 2). The remaining patients $(n=29 / 38)$ underwent quantitative enzymatic testing (after abnormal neonatal screening or clinical suspicion) at laboratories $\mathrm{B}, \mathrm{C}$, and $\mathrm{D}$, in plasma or serum, as described by Wolf et al. (1983) [2]. The normal reference range is $5.0-10 \mathrm{nmol} / \mathrm{min} / \mathrm{mL}$. The following enzyme activity ranges were used for classification of biochemical phenotype: $<0.75$, profound deficiency; $0.75-$ 2.25, partial deficiency; 2.26-4.9, heterozygosity. Values within \pm 0.1 of a cutoff point were classified as borderline. When more than one measurement was available, the highest level was used for classification (Table 2).

\section{BTD gene analysis}

Genomic DNA (gDNA) was extracted from blood collected into EDTA-containing tubes using an Easy-DNA ${ }^{\mathrm{mm}}$ Kit (Invitrogen ${ }^{\mathrm{TM}}$, Carlsbad, CA, USA) in accordance with manufacturer instructions. Exons 2, 3, and 4 and exon/ intron junctions of the BTD gene were amplified and sequenced. Regions with detectable changes were assessed in the patients' parents (data not shown), to confirm

Table 1 Molecular basis of biotinidase deficiency (BD)

\begin{tabular}{l} 
Profound BD \\
\hline Profound deficiency allele
\end{tabular}


Table 2 Biochemical and molecular profile of patients with reduced biotinidase activity $(n=38)$

\begin{tabular}{|c|c|c|c|c|c|c|c|}
\hline Patient & Gender & Allele 1 & Allele 2 & $\begin{array}{l}\text { Expected type } \\
\text { of BD according } \\
\text { to genotype }\end{array}$ & $\begin{array}{l}\text { Type of BD } \\
\text { according to } \\
\text { enzyme activity }^{b}\end{array}$ & $\begin{array}{l}\text { Biotinidase } \\
\text { activity }^{\mathrm{a}}\end{array}$ & $\begin{array}{l}\text { Manner of } \\
\text { diagnosis }\end{array}$ \\
\hline 01 & $\mathrm{~F}$ & c.643C > T (p.L215F) & c.755A > G (p.D252G) & Profound & N/A & $21.88 \mathrm{U}$ & NS \\
\hline $02^{c}$ & M & c.755A > G (p.D252G) & c.755A > G (p.D252G) & Profound & Profound & $\begin{array}{l}0.1 ; 0.4 ; 0.33 ; \\
0.44 ; 0.16 ; 0.32\end{array}$ & $S$ \\
\hline 03 & $\mathrm{~F}$ & c.1612C > T (p.R538C) & c.1612C > T (p.R538C) & Profound & Profound & 0.12 & S \\
\hline 04 & M & c.1330G > C (p.D444H) & c.98_104del7ins3 & Partial & Partial & 1.5 & NS \\
\hline 05 & $\mathrm{~F}$ & c.1330G > C (p.D444H) & $\begin{array}{l}\text { c. [470G > A;1330G >C] } \\
\text { (p. [R157H;D444H]) }\end{array}$ & Partial & Partial & 1.8 & NS \\
\hline 06 & M & c.1330G > C (p.D444H) & $\begin{array}{l}\text { c. }[511 G>A ; 1330 G>C] \\
(p .[A 171 T ; D 444 H])\end{array}$ & Partial & Partial & 1.4 & NS \\
\hline 07 & $\mathrm{~F}$ & c.1330G > C (p.D444H) & $\begin{array}{l}\text { c.[511G > A;1330G >C] } \\
(\text { p. }[\text { A171T;D444H] })\end{array}$ & Partial & $\mathrm{Hz}$ & 2.5 & NS \\
\hline 08 & $\mathrm{~F}$ & c.1330G > C (p.D444H) & $\begin{array}{l}\text { c.[511G > A;1330G >C] } \\
(\text { p. }[\text { A171T;D444H] })\end{array}$ & Partial & N/A & $45.81 \cup$ & NS \\
\hline 09 & $\mathrm{~F}$ & c.1330G > C (p.D444H) & c.594_596delCGT (p.V199del) & Partial & Partial & $1.2 ; 1.9$ & NS \\
\hline 10 & $\mathrm{~F}$ & c.1330G > C (p.D444H) & $\begin{array}{l}\text { c.[595G > A; } 1413 T>C] \\
\text { (p.[V199M;C471C]) }\end{array}$ & Partial & $\mathrm{Hz}$ & 2.8 & NS \\
\hline 11 & M & c.1330G > C (p.D444H) & c.755A > G (p.D252G) & Partial & Partial & 1.7 & NS \\
\hline 12 & $\mathrm{~F}$ & c.1330G > C (p.D444H) & c.755A > G (p.D252G) & Partial & Partial & 1.2 & NS \\
\hline 13 & $\mathrm{~F}$ & c.1330G > C (p.D444H) & c.755A > G (p.D252G) & Partial & $\mathrm{Hz}$ & 2.4 & NS \\
\hline 14 & M & c.1330G > C (p.D444H) & c.755A > G (p.D252G) & Partial & N/A & $51.37 \mathrm{U}$ & NS \\
\hline 15 & M & c.1330G > C (p.D444H) & c.933delT & Partial & Partial & 1.6 & NS \\
\hline 16 & $\mathrm{~F}$ & c.1330G > C (p.D444H) $)^{d}$ & c. $100 G>A^{d}$ & Partial or $\mathrm{Hz}$ & Partial & $1.2 ; 2.04$ & NS \\
\hline 17 & M & $c .1330 G>C(p . D 444 H)^{d}$ & c.643C > T (p.L215F) & Partial or $\mathrm{Hz}$ & $\mathrm{Hz}$ & 2.4 & NS \\
\hline 18 & $\mathrm{~F}$ & c.1330G > C (p.D444H) $)^{d}$ & c. 1629 C > A (p.D543E) ${ }^{d}$ & Partial or $\mathrm{Hz}$ & $\mathrm{Hz}$ & 2.6 & NS \\
\hline 19 & M & c.1413 T>C (p.C471C) & $\begin{array}{l}\text { c.[511G }>A ; 1330 G>C] \\
(p .[A 171 T ; D 444 H])\end{array}$ & $\mathrm{Hz}$ & $\mathrm{Hz}$ & 3.3 & NS \\
\hline 20 & M & c.1595C > T (p.T532M) & $\mathrm{N}$ & $\mathrm{Hz}$ & $\mathrm{Hz}$ & $1.5 ; 2.9 ; 4.4$ & NS \\
\hline 21 & M & c.1330G > C (p.D444H) & c.1330G > C (p.D444H) & $\approx \mathrm{Hz}$ & $\mathrm{Hz}$ & $0.7 ; 3.3$ & NS \\
\hline 22 & M & c.1330G > C (p.D444H) & c.1330G > C (p.D444H) & $\approx \mathrm{Hz}$ & $\mathrm{Hz}$ & 3.7 & NS \\
\hline 23 & M & c.1330G > C (p.D444H) & c.1330G > C (p.D444H) & $\approx \mathrm{Hz}$ & $\mathrm{Hz}$ & $2.8 ; 2.7$ & NS \\
\hline 24 & M & c.1330G > C (p.D444H) & c.1330G > C (p.D444H) & $\approx \mathrm{Hz}$ & N/A & $48.75 \mathrm{U}$ & NS \\
\hline 25 & M & c.1330G > C (p.D444H) & c.1330G > C (p.D444H) & $\approx \mathrm{Hz}$ & N/A & $51.83 \mathrm{U}$ & NS \\
\hline 26 & M & c.1330G > C (p.D444H) & c.1330G > C (p.D444H) & $\approx \mathrm{Hz}$ & N/A & $46.88 \mathrm{U}$ & NS \\
\hline $27^{c}$ & M & c.1330G > C (p.D444H) & c.1330G > C (p.D444H) & $\approx \mathrm{Hz}$ & N/A & $52.73 \mathrm{U}$ & NS \\
\hline 28 & $\mathrm{~F}$ & c.1330G > C (p.D444H) & c.1330G > C (p.D444H) & $\approx \mathrm{Hz}$ & N/A & $40.94 \mathrm{U}$ & NS \\
\hline 29 & $\mathrm{~F}$ & c.1330G > C (p.D444H) & c.1330G > C (p.D444H) & $\approx \mathrm{Hz}$ & N/A & $45.37 \mathrm{U}$ & NS \\
\hline 30 & M & c.1330G > C(p.D444H) & N & $\approx N$ & Borderline $(\mathrm{Hz} / \mathrm{N})$ & 4.9 & NS \\
\hline 31 & $\mathrm{~F}$ & c.1330G > C (p.D444H) & N & $\approx N$ & $\mathrm{~Hz}$ & 3.1 & NS \\
\hline 32 & $\mathrm{~F}$ & c.1330G > C (p.D444H) & $\mathrm{N}$ & $\approx N$ & $\mathrm{~Hz}$ & $3.8 ; 2.7$ & $\mathrm{~S}$ \\
\hline 33 & M & c.1413 T>C (p.C471C) & $\mathrm{N}$ & $N$ & Borderline $(\mathrm{Hz} / \mathrm{N})$ & $0.1 ; 2.6 ; 4.9$ & NS \\
\hline 34 & $\mathrm{~F}$ & $N$ & $\mathrm{~N}$ & $\mathrm{~N}$ & $\mathrm{~Hz}$ & 4.1 & $S$ \\
\hline 35 & $M$ & $\mathrm{~N}$ & $\mathrm{~N}$ & $N$ & $\mathrm{~Hz}$ & 3.7 & $S$ \\
\hline
\end{tabular}


Table 2 Biochemical and molecular profile of patients with reduced biotinidase activity $(\mathbf{n}=\mathbf{3 8})($ Continued)

\begin{tabular}{|c|c|c|c|c|c|c|c|}
\hline 36 & $\mathrm{~F}$ & c.1330G > C (p.D444H) & c.119 T > C (p.L40P) & Unknown & Partial & 1.7 & NS \\
\hline 37 & M & c.1330G > C (p.D444H) & c.479G > A (p.C160Y) & Unknown & Borderline (Partial/Hz) & $0.2 ; 1.7 ; 2.2$ & NS \\
\hline 38 & M & $c .664 G>A(p . D 222 N)$ & $\mathrm{N}$ & Unknown & $\mathrm{Hz}$ & 3.5 & NS \\
\hline
\end{tabular}

${ }^{a}$ The cutoff for filter-paper tests performed at laboratory $A$ is $70 \mathrm{U}$. For quantitative testing in serum or plasma performed at laboratories $B$, $C$, $D$, the measurement unit is $\mathrm{nmol} / \mathrm{min} / \mathrm{mL}$ and the reference range is $5.0-10$. Unless otherwise specified, the unit of enzyme activity is $\mathrm{nmol} / \mathrm{min} / \mathrm{mL}$.

${ }^{\mathrm{b}}$ The following enzyme activity ranges were used for phenotypic classification: $<0.75$, profound deficiency; $0.75-2.25$, partial deficiency; $2.26-5.0$, heterozygosity. If more than one measurement was obtained, the highest value was considered. Values within \pm 0.1 of a cutoff point were classified as borderline.

${ }^{\mathrm{c}}$ Patients with consanguineous parents.

${ }^{d}$ Whether it is in cis or trans configuration with the other variant found remains undetermined.

Novel variants shown in bold type, and synonymous variants, in italics.

$B D$, biotinidase deficiency; F, female; M, male; NS, neonatal screening; S, symptoms; Hz, heterozygosity; N/A, not available; N, normal.

whether variants were in cis or trans. Polymerase chain reaction (PCR) was performed using previously described primers [14] and the following annealing temperatures: $58^{\circ} \mathrm{C}$ for amplicons 2 and $3,59^{\circ} \mathrm{C}$ for $4 \mathrm{a}, 60^{\circ} \mathrm{C}$ for $4 \mathrm{~b}$, and $62^{\circ} \mathrm{C}$ for $4 \mathrm{c}$ and $4 \mathrm{~d}$. PCR products were purified with polyethylene glycol 8000 solution (PEG $800050 \%, \mathrm{NaCl}$ $2.5 \mathrm{M}$ ) and sequenced using a BigDye Terminator v3.1 Cycle Sequencing Kit and ABI 3500 Genetic Analyzer (Applied Biosystems, Foster City, CA, USA). Finally, the resulting sequences were compared with the reference sequence of the BTD gene (NG_008019.1).

For calculation of allele frequencies, the total number of alleles was set at 74, as two patients were the children of consanguineous parents.

A hundred control subjects were tested for the presence of variants c.119 T > C (p.L40P) and c.664G > A (p.D222N) by restriction fragment length polymorphism (RFLP) analysis - allele C of c.119 T > C introduces a site for the restriction enzyme SmaI, whereas allele A of c.664G > A removes a cleavage site for TaqI - and variants c.479G > A (p.C160Y) and p.D444H by direct sequencing of amplicons $4 \mathrm{a}$ and $4 \mathrm{~d}$ respectively, which enabled identification of additional variants in these amplicons.

\section{In silico analysis}

All variants described in patients for the first time in this study were evaluated for pathogenicity by in silico analysis with PolyPhen-2 [15] and SIFT [16] softwares.

\section{Genotype-phenotype association}

Expected biochemical phenotype (e.g., profound DB, partial DB or heterozygous state) was established according to Table 1 only for genotypes composed of recurrent pathogenic variants with a known cis/trans configuration, and that are known to be associated with the phenotype.

\section{Results}

\section{Clinical aspects}

Of the 38 subjects included in the study (Table 2), only two had profound BD. Nine patients had undergone filterpaper screening alone, and thus had unspecified BD. Two patients (5.3\%, patients 02 and 27) had consanguineous parents. Only one subject (patient 03) had a family history suggestive of $\mathrm{BD}$ recurrence - namely, a sister who died at age 3 years with clinical manifestations consistent with $\mathrm{BD}$, but no confirmed diagnosis.

Thirty-three patients were identified by neonatal screening, of whom 27 were on biotin $(10 \mathrm{mg} /$ day); none had clinical manifestations suggestive of $\mathrm{BD}$ at the time of inclusion. Six patients (patients 06, 12, 15, 19, 22, 33) were preterm and had been born between 35 and 36 weeks of pregnancy. Neonatal jaundice was reported for patients 20 and 33. Another five patients had been diagnosed on the basis of clinical suspicion. In these patients, the most common symptoms were visual disturbances, neurological manifestations, and skin lesions. The age at onset of manifestations ranged from 1 day to 10 years, and the age at diagnosis from 40 days to 18 years. All were receiving biotin supplementation (10-20 mg/day) at the time of writing.

\section{Genetic assessment}

A total of 17 different alleles were found among the analyzed patients (Table 2): 13 recurrent pathogenic variants, three novel variants (p.L40P, p.C160Y and p.D222N), and one synonymous variant. No changes were found in exon 3. The most common variants were p.D444H, c.755A > G (p.D252G) and p.[A171T;D444H], with allele frequencies of $50 \%, 9.4 \%$, and $5.4 \%$ respectively.

Twenty-nine patients had two pathogenic variants detected (with cis/trans status ascertained in 26/29), six had only one variant, and three had no pathogenic variants detected. Among patients in whom both classification of biochemical phenotype and genotyping were possible $(n=26 / 38)$, genotyping confirmed the original classification in 16. Discordance between genotype and biochemical phenotype was seen in seven cases: patients 07, 10 and 13 exhibited enzyme activity levels slightly higher (suggestive of heterozygosity) than expected in view of their genotype (suggestive of partial BD); and patients 31, 32, 34 and 35 showed enzyme activity lower (suggestive of heterozygosity) than expected in view of the genotype (no variants found). In three subjects (patients 16, 17 and 18), the unclear cis/trans status prevented the 
confirmation of the biochemical phenotype. In patients 36,37 and 38, genotyping revealed novel variants, thus precluding prediction of biochemical phenotype.

None of the three novel variants described herein were found in controls and two out of them were predicted as damaging by in silico analysis as well. The p.D222N variant had contradictory prediction between the two programs used (damaging by PolyPhen-2 and tolerated by SIFT). The allele frequency of p.D444H in controls was $4 \%$ (six heterozygous and one homozygous individuals for this variant were detected). Other variants found in controls were c.460-7_8insT, c.1171C > T (p.P391S), c.1284C > T (p.Y428Y) and c.1413 T > C (p.C471C) and their frequencies were respectively $0.5 \%, 1.5 \%, 0.5 \%$ and $5.5 \%$.

\section{Discussion}

This study characterized the clinical and molecular profile of Brazilian patients with reduced biotinidase activity and, thus, at risk of BD. Before 2012, neonatal screening for BD was unavailable through the public Unified Health System in the majority of Brazilian states, and was only provided by private laboratories located mainly in the South and Southeast regions of the country, which may have contributed to its underdiagnosis. Paradoxically, studies based on neonatal screening suggest that the overall frequency of BD (profound + partial BD) in Brazil may be among the highest ever reported, ranging from 1:6,843 to 1:62,500 newborns (NB) [17-20]. To the best of our knowledge, only one prior study conducted DNA analysis of Brazilian patients with BD $(\mathrm{n}=21)[18]$.

Two studies conducted in the U.S., in which $92 \mathrm{pa}-$ tients with profound $\mathrm{BD}$ and 19 with partial BD were assessed, showed that the most common $B T D$ variants in the study population were c.98_104del7ins3, c.1612C > T (p.R538C), c.1368A > C (p.Q456H), p.[A171T;D444H] and p.D $444 \mathrm{H}$, which, overall, accounted for approximately $60 \%$ of abnormal alleles found in the sample [12,21]. Taking into account this five-variant panel, p.[A171T;D444H] and p. $\mathrm{D} 444 \mathrm{H}$ account for approximately $55 \%$ of alleles detected in the present study, with the occurrence of variants c.98_104del7ins3 and p.R538C in only one patient each. In our sample, we did not detect the variant p.Q456H, the profound $\mathrm{BD}$ allele most commonly found among children diagnosed by neonatal screening in the U.S. (allele frequency $=28 \%$ ) [21], nor did we find any changes in exon 3. Furthermore, p.D252G appeared to occur more commonly (allele frequency $=9.4 \%$ ) in our sample than in the U.S. population [21]. Our findings corroborate those of Neto et al. (2004) [18], who analyzed the BTD gene in 21 Brazilian patients with reduced biotinidase activity detected by neonatal screening and also found that p.D444H, c.98_104del7ins3, p.[A171T;D444H], and p.D252G were the most prevalent variants; the authors also did not detect variant p.Q456H or changes in exon 3 among their sample. Therefore, we suggest that the profile of genetic variants found among Brazilian patients with BD differs from that found in U.S. patients, although these differences may be partly attributable to the relatively small number of patients with profound $\mathrm{BD}$ included in our sample (c.98_104del7ins3, p.R538C and p.Q546H are classically associated with profound $\mathrm{BD}$ ).

Since the p.D444H variant - usually classified as a partial DB allele - was the most common variant found in our study, our findings also suggest that partial BD is the most common form of $\mathrm{BD}$ in Brazil. We found that allele $\mathrm{C}$ of the variant c.1330G > C or p.D444H constituted $4 \%$ of alleles in healthy individuals, a frequency close to that found in the U.S. population $[22,23]$, where the incidence of profound and partial $\mathrm{BD}$ has been estimated at 1:80,000 NB and 1:31,000-1:40,000 NB respectively [10], and in Western Hungary, where the incidence of profound and partial $\mathrm{BD}$ is 1:97,000 NB and 1:23,000 NB respectively [24].

As previously reported, the association between $B T D$ genotype and biotinidase activity is not absolute [18,25]. In the Greek study conducted by Thodi et al. (2013) [25], for instance, homozygosity for p.D444H was suggested to be associated with partial $\mathrm{BD}$, and not with a $45-50 \%$ reduction of biotinidase activity, as expected. In the present study, among the seven cases of disagreement between the observed and expected biochemical phenotype, we highlight patient 10 because her genotype p.D444H/c.595G > A (p.V199M) and p.V199M/p.V199M have previously been reported in patients with residual biotinidase activity levels of $32 \%$ and $11.5 \%$ respectively [26], and it is possible that the p.V199M variant is not as damaging as other profound BD alleles. Furthermore, patient 31, from Northeast Brazil, and patients 32, 34 and 35 , from the Southeast region, underwent testing at a laboratory in the South region, so their biochemical test results may have been artifactually low due to time constraints or transportation of samples to the laboratory under inadequate conditions, as suggested by Neto et al. (2004) [18]. However, we cannot rule out the presence of changes in a region of the BTD gene not covered by our analyses causing decreased enzyme activity.

In three patients, we were unable to define the cis/ trans status of variant p.D444H in relation to the other variant found. On the basis of enzyme activity, trans status is most probable for patient 16 . For patient 17 , who presented with a biotinidase level suggestive of heterozygosity (but very close to the upper limits of partial DB), only gDNA from her mother, who also presented low biotinidase activity in a dried spot blood sample (data not shown), was available for analysis; as she was found to be a carrier of both p.D444H and c.643C > T (p.L251F) 
variants, the patient can be heterozygous if both variants were inherited on the maternal side (if they were in cis), or have partial $\mathrm{BD}$ if $\mathrm{p} . \mathrm{D} 444 \mathrm{H}$ was inherited from the father and only p.L215F from the mother (in this case, the mother should also exhibit partial DB). Similarly, both parents of patient 18, who is heterozygous for variants p.D444H and c.1629C > A (p.D543E), are heterozygous for p.D444H, but the father is also a carrier of p.D543E; therefore, the patient can be heterozygous if p.D444H and p.D543 are in cis in the paternal allele, or can have partial DB if they are in trans (in which case the father should also exhibit partial DB). A new enzyme activity test in the child and testing of parents (or even analysis of grandparent DNA) could help characterize $\mathrm{BD}$ in this case.

Although the enzyme activity of symptomatic patients 32, 34 and 35 was not consistent with profound or partial BD, biotin treatment was started after other genetic conditions had been ruled out, as the patients' clinical manifestations are consistent with BD and biotin has a good safety profile. Unfortunately, we are not aware whether there was any improvement with treatment. These patients may represent cases of delayed-onset BD, but the absence of variants in exons 2-4 of the BTD gene suggest they do not have $\mathrm{BD}$. Patient 33 is also very interesting, since his biotinidase activity levels were very low on neonatal screening, and gradually approached the normal range thereafter, as would be expected to his genotype. We believe the wide variation in biotinidase levels presented by this patient is mainly explained by premature birth and neonatal jaundice. However, as the first test was performed when he was only 5 days old and the last at age 1 year, some of this variation could also be due to increasing age.

On the basis of the allele frequency of novel variants p.L40P and p.C160Y in controls and of the in silico prediction of pathogenicity, and taking observed enzyme activity into account, these alleles were considered probably damaging, and patients 36 and 37 , who are compound heterozygous for the p.D444H variant, probably have partial BD. Variant p.L40P does not affect the peptide portion that constitutes the mature protein, but affects the signal peptide, which may impair targeting of the enzyme to secretory vesicles, thus resulting in reduced enzyme activity in plasma. Alleles associated with profound BD which affect this region have been described elsewhere $[27,28]$. The effect of variant p.D222N on biotinidase function could not be established clearly from bioinformatics, as we used two different software programs which presented contradictory conclusions regarding this variant. However, the absence of this variant in controls suggests it is probably damaging.

Regarding the other two nonpathogenic polymorphic variants found in controls, c.1171C $>\mathrm{T}$ or p.P391S (rs35034250) and c.1413 T > C or p.C471C (rs3817641), both were found at frequencies similar to those reported in populations of USA and African origin respectively (available at: http://www.ncbi.nlm.nih.gov/snp/).

\section{Conclusion}

Genotyping of Brazilian patients with reduced biotinidase activity broadened current knowledge on the allelic heterogeneity of BD. Furthermore, the high frequency of the p.D444H variant in patients and controls suggest that the incidence of partial BD in Brazil may be higher than worldwide estimates. When enzyme activity approaches the border between partial BD and heterozygosity, sequencing of the BTD gene (starting with analysis of exons 2 and 4) appears to be the most appropriate technique to elucidate the diagnosis in this population. We suggest that parental DNA analysis be carried out whenever the p.D444H variant and another variant are detected in a BD patient.

\section{Abbreviations \\ BD: Biotinidase deficiency; NB: Newborns; PCR: Polymerase chain reaction; PEG: Polyethylene glycol; RFLP: Restriction fragment length polymorphism; F: Female; M: Male; NS: Neonatal screening; S: Symptoms; Hz: Heterozygosity; N/A: Not available; N: Normal; D: Days; M: Months; Y: Years; FIPE: Fundo de Incentivo à Pesquisa e Eventos; HCPA: Hospital de Clínicas de Porto Alegre; CNPq: National Council for Scientific and Technological Development; FAPERGS: Rio Grande do Sul Research Foundation.}

\section{Competing interests}

The authors declare that they have no competing interests.

\section{Authors' contributions}

IVDS conceived of the study, participated in its design and coordination and drafted the manuscript. TB collected clinical information, carried out the molecular analysis, and drafted the manuscript. FS assisted in the interpretation of results. SL participated in the design of the study. The other authors contributed in recruiting participants, collecting samples and data. All authors read and approved the final manuscript.

\section{Acknowledgments}

This study was supported by Fundo de Incentivo à Pesquisa e Eventos (FIPE) - Hospital de Clínicas de Porto Alegre (HCPA), the National Council for Scientific and Technological Development (CNPq), and the Rio Grande do Sul Research Foundation (FAPERGS). The authors would like to thank the staff at the HCPA Inborn Errors of Metabolism Laboratory/Rede EIM, and Mr. Regis Guidobono in particular, for the diagnosis and follow-up of some of the patients included in the sample.

\section{Author details}

${ }^{1}$ Post Graduate Program in Genetics and Molecular Biology, Universidade Federal do Rio Grande do Sul (UFRGS), Porto Alegre, Brazil. ${ }^{2}$ BRAIN Laboratory, Center for Experimental Research (CPE), Hospital de Clínicas de Porto Alegre (HCPA), Porto Alegre, Brazil. ${ }^{3}$ Post Graduate Program in Medicine: Medical Sciences, UFRGS, Porto Alegre, Brazil. ${ }^{4}$ Gene Therapy Center, CPE, HCPA, Porto Alegre, Brazil. ${ }^{5}$ Hospital Infantil Joana de Gusmão, Florianópolis, Brazil. ${ }^{6}$ Medical Genetics Service, Hospital de Clínicas de Porto Alegre (HCPA), Rua Ramiro Barcelos, 2350, 90035-903 Porto Alegre, Brazil. ${ }^{7}$ Universidade Federal de Campina Grande, Campina Grande, Brazil. ${ }^{8}$ Medical Genetics Service, Hospital das Clínicas de Ribeirão Preto, Universidade de São Paulo, São Paulo, Brazil. ' Universidade Estadual de Ciências da Saúde de Alagoas, Maceió, Brazil. ${ }^{10} \mathrm{CTN}$ Diagnósticos, Porto Alegre, Brazil. ${ }^{11}$ Hospital Universitário-Universidade Federal de Santa Catarina, Florianópolis, Brazil. ${ }^{12}$ Department of Genetics, UFRGS, Porto Alegre, Brazil. 
Received: 8 April 2014 Accepted: 5 August 2014

Published: 1 September 2014

\section{References}

1. Hymes J, Wolf B: Biotinidase and its roles in biotin metabolism. Clin Chim Acta 1996, 255:1-11.

2. Wolf B, Grier RE, Allen RJ, Goodman SI, Kien CL: Biotinidase deficiency: the enzymatic defect in late-onset multiple carboxylase deficiency. Clin Chim Acta 1983, 131:273-281.

3. Wolf B, Grier RE, Allen RJ, Goodman SI, Kien CL, Parker WD, Howell DM, Hurst DL: Phenotypic variation in biotinidase deficiency. J Pediatr 1983, 103:233-237.

4. Bay $L B$, de Pinho S, Eiroa HD, Otegui I, Rodriguez R: [The importance of a law on time: presentation of a girl with biotinidase deficiency who was not picked up through the neonatal screening]. Arch Argent Pediatr 2010, 108:e13-e16.

5. Wastell HJ, Bartlett K, Dale G, Shein A: Biotinidase deficiency: a survey of 10 cases. Arch Dis Child 1988, 63:1244-1249.

6. Wolf $\mathrm{B}$ : Clinical issues and frequent questions about biotinidase deficiency. Mol Genet Metab 2010, 100:6-13.

7. Wolf B: Biotinidase deficiency: new directions and practical concerns. Curr Treat Options Neurol 2003, 5:321-328.

8. Suormala T, Wick H, Baumgartner ER: Low biotinidase activity in plasma of some preterm infants: possible source of false-positive screening results. Eur J Pediatr 1988, 147:478-480.

9. Schulpis KH, Gavrili S, Tjamouranis J, Karikas GA, Kapiki A, Costalos C: The effect of neonatal jaundice on biotinidase activity. Early Hum Dev 2003, 72:15-24.

10. Cowan TM, Blitzer MG, Wolf B, Working Group of the American College of Medical Genetics Laboratory Quality Assurance Committee: Technical standards and guidelines for the diagnosis of biotinidase deficiency. Genet Med 2010, 12:464-470.

11. Wolf B: Biotinidase Deficiency. In GeneReviews ${ }^{\mathrm{TM}}$ [Internet]. Edited by Pagon RA, Adam MP, Bird TD, Ardinger HH, Dolan CR, Fong CT, Smith RJH, Stephens K. University of Washington, Seattle: Seattle (WA); 2000. Updated 2013 Dec 5.

12. Swango KL, Demirkol M, Huner G, Pronicka E, Sykut-Cegielska J, Schulze A, Mayatepek E, Wolf B: Partial biotinidase deficiency is usually due to the D444H mutation in the biotinidase gene. Hum Genet 1998, 102:571-575.

13. Wolf B: Biotinidase deficiency: "if you have to have an inherited metabolic disease, this is the one to have". Genet Med 2012, 14:565-575.

14. Wolf B, Jensen KP, Barshop B, Blitzer M, Carlson M, Goudie DR, Gokcay GH, Demirkol M, Baykal T, Demir F, Quary S, Shih LY, Pedro HF, Chen TH, Slonim AE: Biotinidase deficiency: novel mutations and their biochemical and clinical correlates. Hum Mutat 2005, 25:413.

15. Adzhubei IA, Schmidt S, Peshkin L, Ramensky VE, Gerasimova A, Bork P, Kondrashov AS, Sunyaev SR: A method and server for predicting damaging missense mutations. Nat Methods 2010, 7:248-249.

16. Kumar P, Henikoff S, Ng PC: Predicting the effects of coding non-synonymous variants on protein function using the SIFT algorithm. Nat Protoc 2009, 4:1073-1081.

17. Luz GS, Carvalho MD, Pelloso SM, Higarashi IH: [Prevalence of diseases diagnosed by the Program of Neonatal Screening in Maringa, Parana Brazil: 2001-2006]. Rev Gaucha Enferm 2008, 29:446-453.

18. Neto EC, Schulte J, Rubim R, Lewis E, DeMari J, Castilhos C, Brites A, Giugliani R, Jensen KP, Wolf B: Newborn screening for biotinidase deficiency in Brazil: biochemical and molecular characterizations. Braz J Med Biol Res 2004, 37:295-299.

19. Pinto AL, Raymond KM, Bruck I, Antoniuk SA: [Prevalence study of biotinidase deficiency in newborns]. Rev Saude Publica 1998, 32:148-152.

20. Wolf $B$ : Worldwide survey of neonatal screening for biotinidase deficiency. J Inherit Metab Dis 1991, 14:923-927.

21. Norrgard KJ, Pomponio RJ, Hymes J, Wolf B: Mutations causing profound biotinidase deficiency in children ascertained by newborn screening in the United States occur at different frequencies than in symptomatic children. Pediatr Res 1999, 46:20-27.

22. Norrgard KJ, Pomponio RJ, Swango KL, Hymes J, Reynolds T, Buck GA, Wolf B: Double mutation (A171T and D444H) is a common cause of profound biotinidase deficiency in children ascertained by newborn screening the the United States. Mutations in brief no. 128. Online. Hum Mutat 1998, 11:410
23. Bell CJ, Dinwiddie DL, Miller NA, Hateley SL, Ganusova EE, Mudge J, Langley RJ, Zhang L, Lee CC, Schilkey FD, Sheth V, Woodward JE, Peckham HE, Schroth GP, Kim RW, Kingsmore SF: Carrier testing for severe childhood recessive diseases by next-generation sequencing. Sci Transl Med 2011, 3:65ra64.

24. Milankovics I, Nemeth K, Somogyi C, Schuler A, Fekete G: High frequencies of biotinidase (BTD) gene mutations in the Hungarian population. $J$ Inherit Metab Dis 2010, 33(Suppl 3):S289-S292.

25. Thodi G, Schulpis KH, Molou E, Georgiou V, Loukas YL, Dotsikas Y, Papadopoulos K, Biti S: High incidence of partial biotinidase deficiency cases in newborns of Greek origin. Gene 2013, 524:361-362.

26. Wolf $B$, Jensen $K$, Huner $G$, Demirkol M, Baykal T, Divry P, Rolland MO, Perez-Cerda C, Ugarte M, Straussberg R, Basel-Vanagaite L, Baumgartner ER, Suormala T, Scholl S, Das AM, Schweitzer S, Pronicka E, Sykut-Cegielska J: Seventeen novel mutations that cause profound biotinidase deficiency. Mol Genet Metab 2002, 77:108-111.

27. Pomponio RJ, Reynolds TR, Cole H, Buck GA, Wolf B: Mutational hotspot in the human biotinidase gene causes profound biotinidase deficiency. Nat Genet 1995, 11:96-98.

28. Pomponio RJ, Reynolds TR, Mandel H, Admoni O, Melone PD, Buck GA, Wolf $B$ : Profound biotinidase deficiency caused by a point mutation that creates a downstream cryptic $3^{\prime}$ splice acceptor site within an exon of the human biotinidase gene. Hum Mol Genet 1997, 6:739-745.

doi:10.1186/s12881-014-0096-3

Cite this article as: Borsatto et al:: Biotinidase deficiency: clinical and genetic studies of 38 Brazilian patients. BMC Medical Genetics 2014 15:96.

\section{Submit your next manuscript to BioMed Central and take full advantage of:}

- Convenient online submission

- Thorough peer review

- No space constraints or color figure charges

- Immediate publication on acceptance

- Inclusion in PubMed, CAS, Scopus and Google Scholar

- Research which is freely available for redistribution

Submit your manuscript at www.biomedcentral.com/submit
C BioMed Central 